\title{
Trade under Global Value Chains in Africa (Lessons from Asia)
}

\author{
Binene Tshibanda Alice, Zhimin Deng \\ School of Economics and management \\ Zhejiang University of Science and Technology
}

\begin{abstract}
A global value chain refers to a globalized manufacturing process in which the tasks for manufacturing the final product are differentiated and performed in different countries. Due to the high transport and coordination costs, globalized production in Africa is very rare. Most of the goods were made in the country or simply in a workshop. Tackling trade in global value chains is on the high-level political agenda of African countries. Despite trading among global value chains, there is a heated debate as to why some African countries are making progress in global markets and others are not. Some authors have noted that Asia has played an important role and performed well within global value chains. The purpose of this article is to understand the importance African countries place on the global value chain and also to explain why trade has succeeded in African global value chains and why some African countries are unable to interact with global value chains. Despite Asian lessons. The data used in this study was collected through 100 questionnaires and six semi-structured and open interviews with managers of African exporting organizations. For quantitative research, a systematic random sampling method was used to select respondents, while respondents were used for qualitative research. SPSS version 21.0 was adopted for the analysis of quantitative data, while the method for reducing qualitative data. The results show that there is no clear understanding and usual meaning for global value chains. Some African countries are now ranked in Africa in terms of foreign direct investment by the United Nations Conference on Trade and Development (UNCTAD) according to the World Investment Report (2018).
\end{abstract}

Keywords: Global Value Chains, Africa, Asia, Trade, manufacturing.

DOI: $10.7176 / \mathrm{JESD} / 12-4-03$

Publication date: February $28^{\text {th }} 2021$

\subsection{Introduction}

This study focuses on trade in global value chains in Africa: lessons from Asia. It should be noted that international trade has become an important channel for every developed and developing country in the world to achieve sustainable development, which is one of the main goals of the country (Peng, Kang, Liu, Cheng \& Ren, 2020). Today's global economy is characterized by two phenomena, namely the modernization of global value chains and large-scale trade agreements. Global value chains and trade agreements are two sides of the same coin, with the direction of the most favorable trade agreements determined not only by the volume and intensity of international trade, but also by the countries' global value chain structure (Peng, Kang, Liu, Cheng \& Ren, 2020). Global value chains have definitely changed the pattern of international trade and cross-border investment in Africa. Between 1990 and 2015, intermediates used as parts and components were found to increase nearly sixfold in global value chains, with total foreign direct investment increasing about 12 times over the same period (Park, Nayyar \& Low, 2018).

The teachings of Asian countries, such as China, have made it possible through technological advancements for organizations to organize production internationally and in offshore positions across national borders. Kehoe \& Ruhl (2013) found that if the costs of coordinating and transporting intermediate inputs between China and Japan are lower than their pay gap, it is more profitable for a Japanese organization to export certain production jobs to China.

In Africa, African countries such as Uganda, South Africa, the Democratic Republic of the Congo and Nigeria have tackled trade using the global value chain analysis framework used by Gereffi (1999) and Gereffi, Humphrey and Sturgeon (2015). Velde et al., (2015), global value chain analysis is considered a better methodological analysis tool than the chain analysis used in Porter's chain analysis model (Porter 1985) because it focuses on added value by looking at functions within and within the model. . around the company, with an emphasis on the competitiveness of the company, the global value chain analysis focuses not only on the competitiveness of the company, but rather on how the relationships between companies are managed (Hammervoll, 2029) to ensure the competitiveness of the chain as can be achieved completely (Velde et al., 2015).

Different countries define the concept of the global value chain in relation to their political, economic and social context (Mazikana, 2018). The relationship between trade and the global value chain has been the subject of much debate for decades (Carroll and Bucholtz, 2012). All forms of business, large or small, have been accused in one way or another of failing to take into account concerns about the global value chain (Carroll and 
Bucholtz, 2012). Today, the new thinking is that the manufacturing process of any company should focus on the global value chain. According to Reich (2018), a global value chain refers to a globalized manufacturing process in which the tasks for manufacturing the final product are differentiated and performed in different countries.

While much has been written about trade processing in global value chains in Africa, not much research has been done to elucidate both the role and nature of global value chains in African countries such as South Africa. Trade literature shows that academic work related to trade processing is limited among global value chains in Africa. An analysis of the literature on trade refinement in global value chains in Africa shows that the following areas have not been studied: the importance of African countries to the global value chain, why trade has succeeded in African global value chains, and why some African countries can trade in global value chains.

- Therefore, the study tried to answer the following questions:

- What is the significance of the global value chain?

- Why has trading been successful in global value chains?

- Why some African countries cannot handle trade in global value chains, des pite lessons from Asian countries?

\subsection{Literature Review}

A value chain is most commonly defined as the full range of activities which are required to bring a product or service from conception, through the different phases of production delivery to final consumers, and final disposal after use (Kaplinsky \& Morris, 2010). Value chain is a useful unit of analysis seen in the literature on the evolution and organization of the world capitalist economy (Bair, 2018; Tijaja, 2010). After mapping a value chain, researchers can apply it as a case study to analyze the spatially dispersed and organizationally complex global production systems (Tijaja, 2010). Value chain analysis differs from comparable market analytical approaches in that it examines the dynamics of firms / countries within global production networks and focuses on productive systems as opposed to sectors or industries in isolation (Farfan, 2015).

Most importantly, a value chain can be used to analyze how relationships amongst participants are governed, enabling a deeper analysis to be done on the highly abstract notion of economic globalization (Gibbon, Bair \& Ponte, 2018). Gereffi et al. (2015) advanced the value chain research agenda by developing a formal theory of value chain governance. The global value chain theory identified a typology of five governance structures that describe the network relationships linking suppliers in global industries to lead firms (Gereffi et al., 2015; Sturgeon et al., 2018). Gereffi et al. (2015), Frederick and Gereffi (2011) elaborated further and distinguished between five chain governance structure types that firms apply to govern linkages between value chain activities:

Markets; Market governance involves transactions that are relatively simple. Information on product specifications is easily transmitted, and suppliers have the capability to make products with minimal input from buyers. These are typically arms-length exchanges associated with repeat transactions with little or no formal cooperation between actors, and the cost of switching to new partners is low for both producers and buyers. The central governance mechanism is price rather than a powerful lead firm. Modular value chains; Modular governance occurs when complex transactions are relatively easy to codify. Suppliers have the capability to make products to a customer's specifications and take full responsibility for process technology using generic machinery that spreads investments across a wide customer base. This keeps switching costs low and reduces transaction-specific investments "asset specificity" and there forex buyer's need for direct monitoring and control.

Relative value chains; Proportional control occurs when buyers and sellers rely on complex information that cannot be easily transferred or learned. This often requires interaction and exchange of information between the parties. Such connections inspire trust and interdependence, governed by reputation, social and territorial proximity, family and ethnic ties, and the like. It can also be addressed through mechanisms that incur costs for the party in breach of contract (Williamson, 2013). Despite the interdependence, leading companies continue to define requirements and are thus able to exercise some control over suppliers. Manufacturers of relational chains are more likely to supply differentiated products based on quality, geographic origin, or other unique characteristics. Creating a relative relationship takes time and requires a great deal of explicit coordination, which makes switching costs for new partners high.

Hierarchy; this type of management describes chains characterized by vertical integration and management in leading companies that develop and manufacture products in-house. This usually happens when product specifications cannot be codified, products are complex, and no qualified suppliers can be found. This type of governance is also driven by the need to share tacit information between value chain functions and protect important resources such as intellectual property.

Captive value chains; In captivity, chains occur when the ability to encode information and the complexity of product specifications are both high combined with low supplier characteristics. These networks are characterized by the monitoring and control of a leading company, which increases dependence on transactions as leading companies seek to lock suppliers to the exclusion of others from the fruits of their efforts. Suppliers therefore have significant switching costs and are "connected". 
Intra-firm relationships dominate opportunism through the dominance of leading firms, which also ensure that suppliers receive fair treatment and a fair share of the market price to make exits attractive.

Value Chain Theory The concept of "value chain" was first introduced by Michael Porter in his 1985 bestseller "Competitive Advantage: Creating and Maintaining Excellent Performance." At the time, the focus was on creating a competitive advantage for the company or organization to achieve the best performance. The value chain is a high-level model developed by Michael Porter that is used to describe the process by which companies obtain raw materials, add value to raw materials through various processes to create the final product, and then sell the final product to customers. . Related value-added activities that convert inputs into outputs, which in turn contribute to the result and help create a competitive advantage. The value chain typically consists of inbound logistics, manufacturing, outbound logistics, marketing and sales, and after-sales service. These activities are supported by procurement, research and development, human resources management and business infrastructure. The value chain refers to all activities from the receipt of raw materials to after-sales support, which together create and increase the value of the product. The value chain refers to the effort to strengthen mutual benefits between companies by jointly exploiting market opportunities, ie creating and building trust among the participants in the value chain. "A value chain is a model that helps analyze specific functions that allow companies to create value and competitive advantage. A value chain is a chain of operations for a company in a particular industry. A business unit is the right level to build a business. and each activity adds some value to the product. The chain of operations adds more value to the products than the sum of the independent activities. Figure 1.1 below shows the value chain model

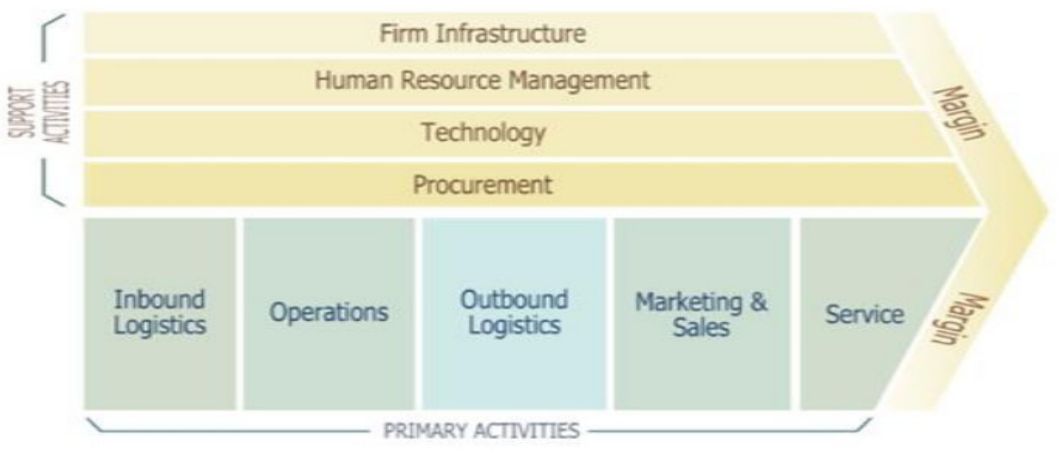

Figure 1.1: The value chain model

\subsection{Global value chains}

Global value chains have become a key trading mechanism and investment in the global economy. Recent estimates suggest that production today is unprecedentedly fragmented and is carried on in global value chains, which accounted for 85\% of world trade in 2016 (UNCTAD Stat 2017). This reorganization of production through global value chains shifts the dynamics of international trade from operating primarily at the country level to inter-firm activities, where each firm adds value sequentially or trades in intermediate goods that contribute to final products elsewhere (Flento and Ponte, 2017; Ponte and Sturgeon, 2014).

\subsection{Global Value Chains as an Economic Strategy}

The African Continent Free Agreement AfCFTA builds on existing regional economic groupings, namely COMESA, SADC, EAC, ECOWAS, IGAD, SEN-SAD, UMA and ECCA. The investigations reveal that, although these preferential agreements were due to tariff adjustments for industrial, agricultural and border measures, subsidies, countervailing measures, anti-dumping duties and trade remedies were not significantly affected. The AfCFTA has covered more policies than PTAs. This reflects the modern deep trade agreements that are typical of those like NAFTA and the EU. This will allow AfCFTA member countries to increase their participation in global value chains (GVCs) and regional value chains. Regional value chains refer to crossborder production in the same economic bloc, while global value chains refer to joint production between countries in different economic blocs. East Asia, Europe and North America are engaged in advanced manufacturing and services, advanced innovation GVCs compared to Latin American, African and Central Asian countries engaged in commodity GVCs and limited manufacturing GVCs.

According to the World Bank, deep trade agreements encourage global value chain and trade related to regional value. This type of agreement also encourages the harmonization of customs procedures across borders, certainty and predictability in trade by removing barriers to trade. AfCFTA is a deep trade agreement in nature that encourages global value chains and regional value chains to increase African productivity and increase economies of scale. Statistics show that manufactured intra-African exports are 36 percent compared to 24 
percent abroad. AfCFTA encourages small and medium-sized enterprises to manufacture and thus encourages these enterprises to participate in regional and global value chains to increase export volumes. World Bank studies reveal that global participation in the value chain can boost economic growth 6-7 times more than a country's traditional exports. The GVC of sub-Saharan Africa has a very low share of intermediate trade in calf skin noble, 3 others. For more information on sub-Saharan African exports going to the original GVCs, you may need to achieve a lower share of agricultural yes commodity VAT, unlike the smaller going to the original GVC: them, you will necessarily achieve a lower share of agricultural yes commodity value added, one size. Exported finished products. This is achieved by adding value by importing intermediaries of finished products before export. Kenya 's integration into global value chains has taken place in the fields of agriculture, belly and industry. Tanzania has been integrated through industry, tourism and transport, although the show in the last two areas of integration in global value chains has been well for him.

Peugeot and Renault have set up a store in Morocco, making Africa one of the global players in the automotive value chain. These African sizes have existed in high score GVC values and truly reflect the GVC success stories of Vietnam and Poland. Sometimes, a year ago, a whole new GVC, one common unit can be used, another unit can contain for the event. Effective customs administration, among many other factors, will become a catalyst for independent trade. Empirical evidence from the World Bank has shown that companies that import and export simultaneously can participate in GVCs. It is common for imports to consist of intermediaries involved in the final product to be exported. Companies integrated into global value chains take advantage of economies of scale and relative and strategic cost restraints only. The nature of GVCs is one in which they are relationships and are largely due to the high degree of specialization among others. Global value chains promote this interdependence between virgins. Therefore, it provides a careful planner of trade policy that should always reflect the interests of other countries. How is it used to happen? The current tariff wars between the United States and China reveal the complexity of international trade. The synchronization of economic activity means that another Earth trade shock will collapse into another country. This has been the case worldwide during the outbreak of the coronavirus. Inflation from the second trade partnership to import the country, yes this is the most important global value chains of virgin central bank machining, together with inflation imports inherent risk management.

The value chain can optimize operations, reduce waste and improve profitability. The development of local value chains contributes to global economic development, in particular by strengthening local industry and creating jobs. When common problems recur, value chains can be used as a diagnostic tool to identify critical problems and barriers for specific groups and then create robust and effective policies and development strategies. This also provides a logical framework for formulating producer intervention strategies and capacity building. In addition, value chains are inherently scalable. Take, for example, the Macadamia Farmers Association in Chipinge, Zimbabwe, or the Banana Farmers Association in the Honde Valley.

The framework used in Zimbabwe can be adopted in other industries to promote economic development and reduce poverty. Another example is Delta Corporation Limited, which in recent years has funded small farmers under the Farmer's Sorghum Contracts Program to improve their ability to grow an essential product in the sorghum beer value chain. In 2016, Cairns revived a farming system that benefited a large proportion of households in Manicaland, Zimbabwe, improving the local production of raw materials in its production. The company emphasized that this measure reduced production costs by reducing the decline in imports and making its products more affordable. Local value chain development makes it possible to identify nuclear rents and entry barriers that determine who benefits from production for different end markets. Given these benefits of advanced value chains, it is therefore clear that some of the economic challenges facing Zimbabwe are the result of dysfunctional value chains whose revenues may have been washed out of the country in the form of raw materials. Zimbabwe is rich in minerals and resources. Unfortunately, most of these are exported raw. These resources require full processing to maximize, as raw raw materials represent less than 10 percent of the value of the processed product.

\subsection{Methodology}

A mixed method has been used in this study. This is the practice of collecting and analyzing data by combining qualitative and quantitative research methods. The research plan was used to record managers' thoughts, assumptions, problems, likes and dislikes regarding trade processing issues in African global value chains (Bhattacherjee, 2012). The survey design allowed respondents to freely complete the questionnaires in private time. In this way, the respondents were encouraged to give honest and truthful answers to the questions in the questionnaire (Borg and Gall, 2008: 73). The 100 respondents to this survey come from exporting companies that use systematic sampling. The questionnaire and interview guide were the main tools for data collection. Quantitative data analysis was performed with SPSS and qualitative data was analyzed by content analysis. 


\subsection{Research Findings}

Statistics showed that $52 \%$ of the respondents were males and $48 \%$ were female.

\begin{tabular}{|l|l|l|l|l|l|}
\hline \multicolumn{2}{|l}{ Managers' gender } & Frequency & Percent & Valid Percent & Cumulative Percent \\
\hline \multirow{4}{*}{ Valid } & Female & 48 & 48 & 48 & 48 \\
\cline { 2 - 7 } & Male & 52 & 52 & 52 & 100.0 \\
\cline { 2 - 7 } & Total & 100 & 100.0 & 100.0 & \\
\hline
\end{tabular}

The results in Table 4.1 above show that there were more men than women. The gender gap shows that there are more men in management positions than women. These results are consistent with those of Mwando, Mamimin, Kanokanga and Chimutungiza (2014). They believe that in addition to the increase in the number of highly educated and skilled women, most of them do not hold top positions.

\subsection{Trade Policy}

$40 \%$ of respondents said they had a trade policy, while $60 \%$ said they had no trade policy to guide them in the organization. It can be concluded from the statistics that commercial practices are unplanned constructions. It can also be concluded that value chains are seen as secondary issues.

\subsubsection{Impact of trade and value chains}

The majority of respondents stated that the importance of international trade has become an important channel for every developed and developing country in the world to achieve sustainable development, which is one of the main goals of the country. Since international trade is often confused with technological innovation and transfer, integration into the global economy is very important for a company's competition and sustainable development. Today's global economy is characterized by two phenomena, namely the modernization of global value chains and large-scale trade agreements.

\subsection{Recommendations}

Countries need to update in globalized production and how many horizontal and vertical updates there are. According to Hidalgo et al. (2017), possible routes for structural upgrade are based on the bilateral relationship of tasks in different industries at different skill levels. The ratio of the two tasks is measured by the probability that the country has shown a relative advantage in both tasks, calculated on the basis of the added value generated by each task. I find that the task is usually more related to other tasks at the same skill level, while the ratio of low to higher skilled tasks is low even in industry. Participating in global value chains is easy, but vertical climbing is a very different process and may require a different recovery policy. I also believe that business service roles, especially in the utilities and logistics industries, have a strong complementarity with production roles and can play an important role in structural upgrades.

\section{References}

[1] Kehoe, T.; Ruhl, K., (2013). How important is the new goods margin in international trade? J. Political Econ.121, 358-392.

[2] Reich, U (2018). Accounting for international trade in value added: A comment on the OECD-WTO project. Econ. Syst. Res.,30, 1-16.

[3] Zhai, F.(2018). China's belt and road initiative: A preliminary quantitative assessment. J. Asian Econ.,55,8492.

[4] Piperopoulos, P.; Wu, J.; Wang, C (2017). Outward FDI, location choices and innovation performance of emerging market enterprises.

[5] Bone, S.; Saxon, T. (2010). Developing Effective Technology Strategies. Res. Manag.,43, 50-58.

[6] Smith, S. Follow me to the innovation frontier? leaders, laggards, and the differential effects of imports and exports on technological innovation. J. Int. Bus. Stud.2014,45, 248-274.

[7] Carroll, A, and Bucholtz, K, A. (2012).Business, Ethics, Sustainability and Stakeholder Management (8thEd).United States of America: South Western Cengage Learning.

[8]Clarkson, M. E. (2013). A stakeholder framework for analyzing and evaluating corporate social performance. Academy of Management Review, 20(1), pp.92-117.

[9] Gereffi, G (2011).Shifting Governance Structures in Global Commodity Chains, with special reference to the Internet. American Behavioral Scientist, 44 (10): 1616-1637.

[10] Gereffi, G. (2014). 'The Organization of Buyer-driven Global Commodity Chains: How U.S. Retailers Shape Overseas Production Networks', in G. Gereffi and M. Korzeniewicz (eds), Commodity Chains and Global Capitalism, Westport, CT: Praeger: 95-122.

[11] Gereffi, G. (2019) 'International Trade and Industrial Upgrading in the Apparel Commodity Chain', Journal of International of Economics, 48: 37 - 70. 